Revista de Estudios Histórico-Jurídicos

[Sección derecho romano]

XLII (Valparaíso, Chile, 2020)

[pp. 107-128]

\title{
LA ACCIÓN DE PETICIÓN DE HERENCIA EN EL DERECHO RO- MANO CLÁSICO: ESTADO DE LA CUESTIÓN Y PERSPECTIVAS*
}

[Hereditary claim in classical Roman law: state of art and perspectives]

\author{
Francisco Javier AnDRÉs SANTOS** \\ Universidad de Valladolid, España
}

\section{RESUMEN}

El presente trabajo se propone aportar una panorámica general sobre los estudios más recientes en torno a la figura de la acción de petición de herencia en el derecho romano clásico, y apuntar algunos de los puntos principales objeto de debate y los necesitados de una mayor tarea investigadora.

\section{Palabras clave}

Acción hereditaria (hereditatis petitio) - senadoconsulto Juvenciano - interdictum quorum bonorum (hereditatis petitio possessoria) - hereditatis petitio partiaria subrogación real.

\section{ABSTRACT}

This paper aims to provide an overview of the present state of art, concerning the hereditary claims in classical Roman Law, as much as to point out the main topics on discussion nowadays and those which are lacking a larger research.

\section{KEY WordS}

Hereditary claim (hereditatis petitio) - senatusconsultum Iuventianum - interdictum quorum bonorum (hereditatis petitio possessoria) - hereditatis petitio partiaria substitution of things.

ReCibido el 28 de abril de 2020 y ACEPTADO el 16 de junio de 2020

\section{INTRODUCCIÓN}

La acción de petición de herencia (es decir, aquella a través de la cual quien se considera heredero legítimo reclama la entrega de los bienes integrantes del patrimonio del difunto por parte de quien se ha hecho con la posesión de los mismos, bien por considerarse también heredero, bien simplemente por creerse con derecho a dichos bienes en contra de quien se relama verdadero heredero) es una de las instituciones más enigmáticas y que suscita más dudas e incertidumbres de todo

* Este artículo se inscribe en el marco del P.I. "La influencia del tiempo en las relaciones jurídicas" (Ref. DER2015-69718-R) y el P. I. "El autor bizantino II” (Ref.: FFI2015-65118C2-1-P), financiados ambos por el Ministerio de Economía y Competitividad (España).

** Catedrático de Derecho Romano, Universidad de Valladolid (España). franciscojavier. andres@uva.es 
el derecho civil. Para empezar, su propia naturaleza híbrida entre institución civil sustantiva y figura procesal ya ofrece una seria dificultad a la hora de afrontar su regulación. Por otro lado, de entre las propias acciones, se trata de una de las más complejas, ya que se busca con ella la restitución del patrimonio relicto mediante un solo acto procesal, aunque en el seno de dicho patrimonio convivan bienes y derechos de muy distinta naturaleza jurídica. Este mismo hecho conduce a que, en muchos casos, resulte muy difícil de precisar tanto lo que es verdadero objeto de la acción, como quiénes están legitimados, tanto desde el punto de vista activo como pasivo, para el ejercicio de la misma, así como numerosos otros puntos que permanecen en una zona de penumbra, como, por ejemplo, el momento en que es posible ejercitar la acción o los plazos de prescripción de esta.

A estas dificultades intrínsecas que presenta la figura se añade el hecho de que, en muchos ordenamientos jurídicos (como es el caso del español ${ }^{1}$ ), no existe un desarrollo legislativo ni siquiera de sus elementos fundamentales, de modo que su regulación práctica se deja enteramente a la labor de la doctrina y la jurisprudencia, que a grandes rasgos se han limitado a actualizar los elementos normativos procedentes de la tradición histórica. De ahí, por tanto, la pertinencia de volver la mirada a esa tradición, que en nuestro caso no es otra que la del derecho romano clásico, en su versión estilizada por Justiniano.

En el derecho romano, aparte de las complejidades dogmáticas intrínsecas que acompañan a esta figura, se añade el hecho de que, debido a las vicisitudes de su desarrollo histórico secular y a las propias peculiaridades constructivas de ese ordenamiento a lo largo de su historia, no nos encontramos ante un solo modelo de acción de petición de herencia como el que se maneja en el derecho moderno, sino ante diversas fórmulas que, aunque sirven al mismo objetivo (la restitución de los bienes hereditarios a su heredero legítimo), presentan características propias y dan lugar a solapamientos y dislocaciones de difícil encaje. Su comprensión se hace aún más difícil teniendo en cuenta el estado fragmentario en que se encuentran los textos que se nos han transmitido, aun cuando fuera esta una materia de atención preferente y aguda interpretación por parte de los juristas romanos.

A la vista de estas circunstancias, no es raro que esta institución haya sido objeto de la atenta mirada de los romanistas desde los inicios de la era histórico-crítica de estudio de las fuentes romanas. Ha habido numerosos intentos de dar una visión comprehensiva y coherente del desarrollo y composición de esta figura, sobre todo en la época clásica, sin que hasta el momento se haya alcanzado una posición unánime en la doctrina al respecto. De hecho, en los últimos años han aparecido una serie de trabajos que han tratado de aclarar diversos aspectos enigmáticos de esta figura y dar una nueva visión de conjunto más acorde con el modo más moderno de leer los textos jurisprudenciales romanos. Sin embargo, como hemos de ver, en algunos puntos las dudas e incertidumbres siguen estando presentes, $y$

${ }^{1}$ En derecho español solo existen tres artículos del Código Civil (192, 1016 y 1021) que hacen referencia a esta figura, limitándose a una mera alusión a su existencia. Sobre el tema, en la doctrina española, puede consultarse, últimamente, Codina Rossa, Maria Dolors, La acción de petición de herencia (Barcelona, 2007). 
en ocasiones cunde ya el escepticismo respecto a nuestras verdaderas posibilidades de aclarar algunas de las serias contradicciones que encontramos en las fuentes.

El objetivo de este trabajo es, simplemente, poner al día el estado de la investigación sobre este tema en este momento, y tratar de apuntar cuáles son los puntos en los que conviene seguir profundizando y aquellos en los que el estado de las fuentes no permite ir mucho más allá. Aquí nos hemos limitado a la figura de la acción hereditaria por excelencia (la hereditatis petitio), que es la que marca la pauta de todo el tratamiento dogmático de la materia, y hemos dejado de lado los otros instrumentos que, a semejanza de la hereditatis petitio, pero con sus propias peculiaridades cada uno, fueron suscitándose a lo largo de la historia del derecho romano, esto es: la hereditatis petitio partiaria, para el caso de que el heredero solo lo fuera de una porción o cuota de la herencia; el interdictum quorum bonorum (más tarde cruzado con una hereditatis petitio possessoria, probablemente ya a lo largo de la época clásica tardía) en favor del bonorum possessor protegido por el pretor; y la hereditatis petitio fideicommissaria, a favor del fideicomisario universal. Todos ellos merecerían una atención específica, pero, por razones de espacio, hemos debido dejarlos fuera de nuestra consideración aquí, al igual que algunos extremos controvertidos de la hereditatis petitio, como es el caso de su concurrencia con las acciones singulares del heredero, o el régimen de prescripción de la acción. Asimismo, tanto por razones expositivas como por el hecho de su menor influencia en la tradición histórica de la institución, prescindiremos del análisis de las cuestiones puramente procedimentales de la acción, limitándonos exclusivamente a las jurídico-sustantivas.

\section{CONCEPTO Y NATURALEZA JURÍDICA}

1. Por efecto de la successio, un heredero civil dispone de todas las acciones reales y personales transmisibles para las que su causante hubiera estado activamente legitimado ${ }^{2}$. Asimismo, en cuanto tal heredero, tiene legitimación propia y originaria para una acción de carácter general, la hereditatis petitio (s. m. D. 5 , 3: De hereditatis possessione; C. 3, 31: De petitione hereditatis), con la que el heres hace valer su derecho hereditario frente a cualquiera que posea, en todo o en parte, los bienes relictos, y pretende, consiguientemente, la restitución de la hereditas en su conjunto, o de una parte de ella.

2. Al igual que el propietario quiritario hace valer su derecho de propiedad sobre la cosa y reclama su restitución mediante la rei vindicatio en cuanto acción s i n g u l a r, así también el heredero reclama su herencia mediante esta acción $\mathrm{u} \mathrm{n}$ ive r s al (actio de universitate o ad universitatem, frente a la rei vindicatio

${ }^{2}$ Successio in locum o successio in universum ius defuncti: Iul. D. 50, 17, 62: Hereditas nibil aliud est quam successio in universum ius quod defunctus habuerit; asimismo, Gai. D. 50, 16, 24. Successio in locum: Gai. 4, 34; cfr. Ulp. D. 12, 2, 7; Paul. D. 2, 13, 9, 1; 18, 1, 76, 1; 28, 5, 9, 12; 41, 3, 4, 15; 50, 17, 177 pr.; Pap. D. 44, 3, 11; Scaev. D. 44, 3, 14; CI. 4, 64, 1 (Gord., 238); 5, 73, 1 (Gord., 238); 7, 36, 1 (Gord., 238); PS. 3, 3b, 10; 4, 8, 12; Tit. Ulp. 23, 3; 26, 2. 
como actio singularis) $)^{3}$. En principio se trata, por tanto, de una actio in rem ral- $^{4}$ cada sobre el modelo de la rei vindicatio, si bien la concepción de su naturaleza es una cuestión problemática, en función de la consideración sobre su objeto (hereditas) $)^{5}$.En una primera época, cuando la hereditas era concebida como una suma de cosas materiales singularmente determinadas (res corporales) sobre las que el heredero actuaba como dominus $^{6}$, la acción presentaba un genuino carácter real ${ }^{7}$, que se conserva en época clásica con matices ${ }^{8}$ (incluso la propia denominación de petitio -en vez de vindicatio - no parece carente de significación, denotando quizá cierta tibieza en cuanto a su carácter real ${ }^{9}$ ). Sin embargo a medida que se

${ }^{3}$ Ulp. D. 6, 1, 1 pr. Expresión a todas luces atécnica, pero genuina ( $c f r$. Voci, Pasquale, Diritto ereditario romano [2a ed., Milano, 1963], I, p. 148 n. 20; KASER, Max, Das römische Privatrecht [= RPR., 2a ed., vol. I, München, 1971; vol. II, München, 1975] I, p. 735 n. 2, frente a las sospechas de itp. (por todos, AlberTARIo, Emilio, "Actio de universitate" e "actio specialis in rem" [1919], ahora, en ÉL MISMO, Studi di diritto romano [Milano, 1946], IV, pp. 65 ss., 219 ss., 385 ss.); con todo, encontró amplio eco en la jurisprudencia postclásica (CTh. 4, 14, 1 pr. [Hon.-Theod., 424] = CI. 7, 39, 3 itp.) y bizantina (schol. a Bas. 41, 3, 38; schol. 2 a Bas. 42, 1, 10; schol. 16 a Bas. 42, 1, 20). Véase más lit. en: Quadrato, Renato, voz Petizione di eredità (diritto romano), en ED., 33 (Milano, 1983) p. 609 n. 1; SIRACUSA, Raffaella, "L'actio de universitate" nell'ambito della concezione romana dell' "hereditas" come "universitas", en SDHI., 66 (2000), pp. 119 ss. (con más lit.); LA MISMA, Il fenomeno delle "actiones de universitate” tra diritto classico e diritto bizantino, en Il diritto giustinianeo fra tradizione classica e innovazione Atti del Convegno Cagliari, 13-14 ottobre 2000 (Cagliari, 2003), pp. 271 ss.

${ }^{4}$ Así también vindicare hereditatem: Gai. 2, 20; Paul. D. 5, 2, 17 pr./19; 5, 3, 8; 35, 3, 4, 1; 48, 20, 7, 4; Ulp. D. 5, 4, 1, 1; 23, 3, 5, 5; 36, 1, 3, 5; 38, 17, 2, 2; 40, 3, 2; Pap. D. 20, 1, 3 pr.; Scaev. D. 28, 5, 83(82); Iul. D. 37, 11, 8, 1; 40, 5, 47, 4; 48, 4, 11; Mod. D. 40, 5, 12, 2; Marcian. D. 47, 19, 3; Gai. D. 49, 14, 14; Iul.-Pomp. D. 49, 14, 35. Véase más lit. en KASER, Max, RPR, I, p. 104 n. 1.

${ }^{5}$ Kaser, Max, RPR., I, p. 735 (con lit. en n. 5); Él mismo, RPR., II, p. 545; Watson, Alan, The Law of Succession in the Later Roman Republic (Oxford, 1971), p. 198; QuAdRATO, Renato, voz Petizione, cit. (n. 3), pp. 610 s.; De LA Rosa, Pelayo, Hereditatis petitio, en Estudios Iglesias (Madrid, 1978), III, p. 1257; Casinos Mora, Francisco Javier, De "Hereditatis Petitione". Estudios sobre el significado y contenido de la herencia y su reclamación (Madrid, 2006), pp. 69 ss.

${ }^{6}$ Inst. Iust. 2, 19, 7: veteres enim heredes pro dominis appellabant; cfr. además Gai. 2, 157; 3, 154a; Ulp. D. 9, 2, 11, 6; Paul. D. 28, 2, 11 pr.; PS. 4, 8, 6; Fest. 99; Gell. 1, 9, 12; Plaut. Men. 477. Sobre esta concepción 'materialista' de la hereditas, véase BonfanTe, Pietro, Corso di diritto romano. VI: Le successioni. Parte generale (Roma, 1930), pp. 98 ss.

${ }^{7} \mathrm{Al}$ respecto, Casinos Mora, Francisco Javier, De Hereditatis, cit. (n. 5), pp. 76 ss. (con lit. y fuentes).

${ }^{8}$ Ulp. D. 5, 3, 25, 18; Paul. D. 6, 1, 27, 3. Véase lit. en LongO, Giannetto, L'hereditatis petitio (Padova, 1933), pp. 72 ss.; BIONDI, Biondo, Diritto ereditario romano: parte generale (Milano, 1954), pp. 383 ss.; KASER, Max, Die Passivlegitimation zur "hereditatis petitio", en ZSS., 72 (1955), pp. 91 ss.; SCHWARZ, Fritz, Studien zur hereditatis petitio, en TR., 24 (1956), pp 279 ss.; Talamanca, Mario, Istituzioni di diritto romano (Milano, 1990), p. 702; Impallomeni, Gianbattista, voz Successioni. Diritto romano, en NNDI., (Torino, 1971), XVIII, p. 710; Quadrato, Renato, voz Petizione, cit. (n. 3), pp. 611 s.; De la Rosa, Pelayo, cit. (n. 5), p. 1257; Casinos Mora, Francisco Javier, De Hereditatis, cit. (n. 5), pp. 79-92. Cfr., sin embargo, Paul. D. 5, 3, 4; Gai. D. 5, 3, 41; 29, 4, 16; además, Gayo no la incluye en el elenco de acciones reales y personales de Gai. 4, 2-3. Contra su consideración como actio in rem, véase lit. en KaSER, Max, RPR., I, p. 735 n. 3.

${ }^{9}$ Pap. D. 44, 7, 28; Ulp. D. 50, 16, 178, 2; pero cfr. PS. 4, 1, 18; Flor. D. 46, 4, 18, 1; Iul. 
produce la d e s m a t e r i a 1 i z a c i ó n de la hereditas ${ }^{10}$ y esta es clasificada entre las res incorporales (ius) ${ }^{11}$, su condición de actio in rem se va desdibujando y empieza a verse como integrada en una categoría intermedia (actio personalis mixta) con respecto a la summa divisio de los genera actionum ${ }^{12}$ entre actiones in rem y actiones in personam, con tendencia a atribuirle carácter personal y de buena fe en época justinianea ${ }^{13}$.

\section{OBJETO DE LA ACCIÓN}

1. El objeto de la acción es la hereditas como conjunto (universitas) ${ }^{14}$. El actor persigue con ella, pues, todo lo que está comprendido en la hereditas, ya sean corpora en dominio quiritario (dominium ex iure Quiritium) o en propiedad pretoria

D. 46, 8, 23; Call. D. 47, 21, 3 pr.; Inst. Iust. 3, 29, 2. Vease más lit. en Quadrato, Renato, voz Petizione, cit. (n. 3), pp. 611 s.; De la Rosa, Pelayo, cit. (n. 5), p. 1256; Casinos Mora, De Hereditatis, cit. (n. 5), pp. 82-84. Sobre 'petitio', véase KASER, Max - HACKL, Karl, Das römische Zivilprozessrecht (2a ed., München, 1996), pp. 236 y n. 31-32; además, BEHrEnds, Okko, Die Trichotomie "actio, petitio, persecutio". Ihre Bedeutung für das Verhältnis zwischen philosophischer Rhetorik und klassischer Jurisprudenz und deren Theorie des prozessabwendenden Vergleichs, en Hausmann, Jost - Krause, Thomas (eds.), "Zur Erhaltung guter Ordnung". Beiträge zur Geschichte von Recht und Justiz. Fs. Sellert (Köln - Weimar - Wien, 2000), pp. 11 ss.

${ }^{10} \mathrm{Al}$ respecto, véase AmBrosino, Rodolfo, In iure cessio hereditatis. Spunti per la valutazione della hereditas, en SDHI., 10 (1944), pp. 82 ss.; ALBANESE, Bernardo, La successione ereditaria in diritto romano antico, en AUP., 20 (1949), pp. 382 ss.; KASER, Max, RPR., I, p. 673 s.; crítico, Roвbe, Ubaldo, La "successio" e la distinzione fra "successio in locum" e "successio in ius" (Milano, 1965), I, pp. 71 ss.

${ }^{11}$ Sen. benef. 6, 5, 3; Gai. 2, 14; Pap. D. 5, 3, 50; Ulp. D. 8, 4, 13 pr.; 28, 5, 3, 3; 28, 5, 9 , 12; 37, 1, 3 pr. y 1; 41, 2, 13, 4; Paul. D. 41, 3, 4, 15; Pomp. D. 50, 16, 119, 178; Afric. D. 50, 16, 208; Paul. D. 2, 13 , 9, 1; 50, 17, 177 et al.; con todo aún Cic. top. 6.29: Hereditas est pecunia [...] (atécnico, según KASER, Max, Controversiam movere, en St. Sanfilippo [Milano, 1982], II, p. 252 n. 166, frente a Schulz, Fritz, Prinzipien des römischen Rechts [München, 1934], p. 32).

${ }^{12}$ CI. 3, 31, 7 pr. (Diocl., 294-305): 'cum-compellat' itp.? (v. Index Itp. [Broggini], 66; cfr. KASER, Max, RPR., II, p. 545 n. 10). Véase más lit. en LIEBS, Detlef, Gemischte Begriffe im römischen Recht, en Index, 1 (1970), pp. 153 y n. 88; Quadrato, Renato, voz Petizione, cit., (n. 3), pp. 610; De la Rosa, Pelayo, cit. (n. 5), p. 1257; Casinos Mora, Francisco Javier, De Hereditatis, cit. (n. 5), pp. 70 s. y 87 ss.

${ }^{13}$ C. 3, 31, 12, 3 (Iust., 530); Inst. Iust. 4, 6, 28. Más lit. en KASER, Max, RPR., II, p. 545 n. 11; D’Ors, Álvaro, Derecho privado romano (10a ed., Pamplona, 2004), p. 337.

${ }^{14}$ Ulp. D. 5, 3, 18, 2 - 20, 5; 5, 3, 20, 10; 6, 1, 1 pr.; 36, 1, 17 (16), 2; 43, 1, 1 pr.; 43, 2, 1, 1; Tryph. D. 29, 1, 18 pr.; Afr. D. 50, 16, 208; Ep. Gai. 2, 2 pr.; Gai. FA. 61-63 et al. Véase más lit. en KASER, Max, RPR., I, p. 304 y n. 5, pp. 673 s. y n. 11; RPR., II, p. 470 y nn. 5-6; Catalano, Pierangelo, Diritto e persone: studi su origine e attualità del sistema romano (Torino, 1990), I, pp. 167 ss.; ANDRÉs SANTOS, Francisco Javier, Subrogación real y patrimonios especiales en el derecho romano clásico (Valladolid, 1997), pp. 49-51; CASTro SÁEnZ, Alfonso, La herencia yacente en relación con la personalidad jurídica (Sevilla, 1998), pp. 27 ss., 45 s.; SIRACUSA, Raffaella; L'actio de universitate, cit. (n. 3), pp. 119 ss.; LA MISMA, La nozione di "universitas" in diritto romano (Milano, 2016); Casinos Mora, Francisco Javier, De Hereditatis, cit. (n. 5), pp. 43 ss. (con más lit. y fuentes). 
(in bonis habere), o bien iura (créditos) ${ }^{15}$, aun cuando hubiesen sido adquiridos para la herencia durante el periodo de hereditas iacens ${ }^{16}$.

2. Se incorporan también todos los aumentos obtenidos por las cosas hereditarias antes o después de producirse la aceptación por el heredero, siempre que se deban a causas extrínsecas ${ }^{17}$, incluidos aquellos derivados de daños causados a las cosas hereditarias ${ }^{18}$, y los frutos generados antes de la litis contestatio, incluidos también los de las cosas dadas en prenda al causante, con independencia del estado de buena o mala fe el poseedor demandado ${ }^{19}$. Asimismo, se incluyen las adquisiciones realizadas por medio de esclavos hereditarios ${ }^{20}$ y los bienes obtenidos a cambio de res hereditariae (res succedit in locum pretii, et pretium in locum rei), siempre que la adquisición sea por cuenta y en interés de la herencia (causa hereditatis) ${ }^{21}$,

${ }^{15}$ Ulp. D. 5, 3, 18, 2 - 20, 5; 5, 4, 1, 1; 44, 2, 7, 5; Pap. D. 5, 3, 50 pr. Más lit. en Kaser, Max, RPR., I, p. 737; Quadrato, Renato, voz Petizione, cit. (n. 3), p. 611; Andrés Santos, Francisco Javier, Subrogación, cit. (n. 14), pp. 51 ss., 76 s.; CASTRO SÁENZ, Alfonso, La herencia, cit. (n. 14), p. 45; Casinos Mora, Francisco Javier, De Hereditatis, cit. (n. 5), pp. 49, 69. Cfr. infra n. 45. No se comprenden las servidumbres, pero cabe la acción singular correspondiente: Paul. D. 5, 3, 1 y 3 .

${ }^{16}$ Paul. D. 2, 14, 27, 10; 28, 5, 53; 41, 2, 1, 5 ; 46, 4, 11, 2; Ulp. D. 6, 2, 9, 6; Pap. D. 41, 3, 44, 3 - 45, 1; Labeo en Iav. D. 28, 5, 65; Iul. D. 44, 7, 16. Véase más lit. en Kaser, Max, RPR., I, pp. 720 s.; CASTro SÁEnZ, Alfonso, La herencia, cit. (n. 14), pp. 69 ss.

${ }^{17}$ Ulp. D. 3, 5, 3, 6; 5, 3, 20, 3; 50, 16, 178, 1; Hermog. D. 41, 1, 61 pr. Más lit. en Kaser, Max, RPR., I, pp. 720 s.; CASTro SÁEnZ, Alfonso, La herencia, cit. (n. 14), pp. 54 ss.

${ }^{18}$ Paul. D. 5, 3, 36, 2; Iul. D. 5, 3, 55; 9, 2, 13, 2 pr.; pero $c f r$. Ulp. D. 5, 3, 20, 4. Más lit. en KASER, Max, RPR., I, p. 738 y n. 31;

${ }^{19}$ Ulp. D. 5, 3, 13, 7 ; 5, 3, 20, 3 ; 5, 3, 25, 20 ; 5, 3, 27 pr.; 5, 3, 29; Pap. D. 5, 3, 51, 1; 22, 1, 34; Paul. D. 5, 3, 26; 5, 3, 36, 5; 5, 3, 40, 1; Iul. en Gai. D. 5, 3, 4, 1; Afr. D. 5, 3, 56; CI. 3, 31, 2 (Sev.-Ant., 200); pero cfr. Ulp. D. 5, 3, 20, 14. Véase al respecto KaSER, Max, $R P R$. I, 737 y n. 26; Él MISMO, RPR., II, pp. 114, 116; ÉL MISMO, Nochmals über Besitz und Verschulden bei den actiones in rem, en ZSS. 98 (1981), p. 116; LIEBS, Detlef, cit. (n. 12), pp. 152 ss.; Müller-Ehlen, Martina, Hereditatis petitio. Studien zur Leistung auf fremde Schuld und zur Bereicherungshaftung in der römischen Erbschaftsklage (Köln, 1998), p. 7; CARDILLI, Riccardo, La nozione giuridica di "fructus" (Napoli, 2000), pp. 300 ss.; ZucCOTтI, Ferdinando, "Fruges fructusque": (studio esegetico su D. 50.16.77): per una ricerca sulle origini della nozione di "frutto" (Padova, 2000), pp. 97 ss.; GONZÁlEZ RoldÁn, Yuri, La responsabilidad del poseedor de buena fe respecto a los frutos e intereses en la perspectiva del senadoconsulto Juvenciano, en Anuario Mexicano de Historia del Derecho, 15 (2003), pp. 701 ss.; ÉL MISMO Il senatoconsulto "Q. Iulio Balbo et P. Iuventio Celso consulibus factum" nella lettura di Ulpiano (Bari, 2008), pp. 241 ss.; Casinos Mora, Francisco Javier, De Hereditatis, cit. (n. 5), pp. 151, 153.

${ }^{20}$ Paul. D. 5, 3, 32.

${ }^{21}$ Ulp. D. 5, 3, 18 pr.; 20 pr.- 2; 33, 1; Gai. D. 5, 3, 35; Paul. D. 5, 3, 36 pr.; Iavol. D. 5, 3, 48 et al. Véase lit. en KASER, Max, RPR., cit., I, p. 738 y n. 29; ÉL MISMO, RPR., II, p. 546 y n. 20; SCHIPANI, Sandro, Responsabilità del convenuto per la cosa oggetto di azione reale (Torino, 1971), pp. 174 ss.; Quadrato, Renato, voz Petizione, cit. (n. 3), p. 614.; Selb, Walter, en Honsell, Heinrich - Mayer-Maly, Theo - Selb, Walter, Römisches Recht, aufgrund des Werkes von Paul Jörs, Wolfgang Kunkel und Leopold Wenger (Berlin, 1987), p. 545; WeLLE, Arno, "In universalibus pretium succedit in locum rei, res in locum pretii". Eine Untersuchung zur Entwicklungsgeschichte der dinglichen Surrogation bei Sondervermögen (Berlin, 1987), pp. 33 ss.; ANDRÉs SANTOS, Francisco Javier, Subrogación, cit. (n. 14), pp. 76 ss., 110 ss.; Müller-Ehlen, Martina, cit. (n. 19), p. 353; Casinos Mora, Francisco Javier, La repercusión del senadoconsulto Juvenciano en materia de reclamación de herencia, en REHJ., 23 (2001), pp. 59 ss.; Él MISMO, De Hereditatis, cit. (n. 
para apreciar lo cual se hace una valoración objetiva de la gestión realizada por el poseedor con criterios análogos a los de la negotiorum gestio ${ }^{22}$. Así, se incluye lo obtenido por el cobro de créditos hereditarios ${ }^{23}$, pero el demandante puede optar entre aceptar el pago y reclamar lo obtenido al poseedor, o no aceptarlo y exigirlo nuevamente del deudor hereditario ${ }^{24} \mathrm{y}$, en el caso de haber concedido créditos a terceros con medios de la herencia, queda a la elección del demandante la aceptación del crédito o reclamar la suma del capital ${ }^{25}$. Si el poseedor ha pagado deudas de la herencia hereditatis causa, pueden imputarse los pagos ${ }^{26}$, pero, si la deuda hereditaria lo fuese a favor del mismo poseedor, solo podrá deducirla por compensación si está de buena $\mathrm{fe}^{27}$. No se computa, en cambio, lo que se hubiera cobrado o pagado indebidamente ${ }^{28}$. Con todo, esta materia en su conjunto fue objeto de una modulación desde el siglo II d. C. a través del SC 'Iuventianum' (véase más adelante en el texto).

3. Con esta acción también se persiguen las cosas corporales que no son de la herencia, pero cuyo riesgo compete al heredero, como las que habían sido pignoradas al causante, o las que le fueron entregadas en comodato o en depósito $^{29}$. El actor puede conseguir todo esto sin necesidad de indicarlo, especificarlo o describirlo expresamente en su demanda, puesto que va comprendido en la hereditas como tal ${ }^{30}$.

4. Puesto que lo perseguido es la hereditas considerada como conjunto universal, no es relevante el hecho de que el demandado, en realidad, solo tenga una cosa hereditaria concreta en su poder: la cuestión importante es que con esa posesión el demandado está impugnando la condición de heredero del demandante $y$, en consecuencia, este puede defender su derecho hereditario a través de esta acción, si bien lo único que obtendrá del demandado, en caso de que prospere la

5), pp. 133 ss. y n. 348; GonZÁlez RoldÁn, Yuri, Il senatoconsulto “Giuvenziano”, en SDHI., 72 (2006), pp. 118 ss., 158 ss.

${ }^{22}$ Talamanca, Mario, Istituzioni, cit. (n. 8), p. 704; Andrés Santos, Francisco Javier, Subrogación, cit. (n. 14), p. 126 y nn. 286-287; MÜLLER-EHLEN, Martina, cit. (n. 19), pp. 201 ss.; con dudas Kaser, Max, RPR., II, p. 547 n 21.

${ }^{23}$ Ulp. D. 5, 3, 16, 1; 25, 18; 31, 5. Lit. al respecto: Andrés SANTOS, Francisco Javier, Subrogación, cit. (n. 14), pp. 58 s., 72 s. y n. 101, 129 s., 135 s.; GonZÁlEZ Roldán, Yuri, Il senatoconsulto, cit. (n. 19), pp. 161 s., 158 ss.

${ }^{24}$ Iul. en Ulp. D. 5, 3, 31, 5. Véase sobre el tema Andrés Santos, Francisco Javier, Subrogación, cit. (n. 14), pp. 129 s.

${ }^{25}$ Iul. en Paul. D. 5, 3, 30. Véase sobre el tema Andrés SANTOS, Francisco Javier, Subrogación, cit. (n. 14), pp. 101 s.; MÜller-Ehlen, Martina, cit. (n. 19), pp. 246 s.

${ }^{26}$ Ulp. D. 5, 3, 31 pr.; CI. 3, 31, 5 (Ant., 213). Sobre la cuestión, véase AndrÉs SANTOS, Francisco Javier, Subrogación, cit. (n. 14), pp. 67 s.; Müller-Ehlen, Martina, cit. (n. 19), pp. 110 ss., 134 ss.

${ }^{27}$ Ulp. D. 5, 3, 31, 1. Sobre el tema, KaSER, Max, RPR., I, p. 738; AndrÉs Santos, Francisco Javier, Subrogación, cit. (n. 14), p. 123 n. 279.

${ }^{28}$ Iul. en Ulp. D. 5, 3, 20, 18; cfr. Gai. D. 5, 3, 17; Pap. D. 12, 6, 3 (legados).

${ }^{29}$ Paul. D. 5, 3, 19 pr. Sobre ello, véase KaSER, Max, RPR., I, p. 738; SELB, Walter, cit. (n. 21), p. 545; Müller-Ehlen, Martina, cit. (n. 19), p. 7

${ }^{30}$ Ulp. D. 5, 3, 18, 2; 44, 2, 7, 4 . 
acción, será la cosa o cosas específicas que este poseyera ${ }^{31}$. Por la misma razón, si el demandado dejó de poseer algo de la hereditas que poseía, y después empezó a poseer otras cosas, también estas quedan automáticamente incluidas en la petición inicial $^{32}$. Puede darse el caso, incluso, de que, en el momento de ser demandado un sujeto, este no posea nada de la herencia (en cuyo caso en principio la demanda está mal formulada), pero que, en el transcurso del proceso, comience a poseer algo de aquella; en tal caso, el sujeto se considerará correctamente demandado y, si el actor prueba su derecho, el demandado deberá ser condenado ${ }^{33}$.

\section{LEGITIMACIÓN ACTIVA}

1. La legitimación activa para ejercitar la acción se atribuye a quien invoca que le corresponde la herencia con arreglo a la ley de las XII Tablas o en virtud de un testamento hecho conforme a derecho, es decir, al heres, ya sea testamentario, contra testamento o intestado, ya necesario o voluntario, siempre que sea heredero único $^{34}$. En la legis actio sacramento in rem correspondía exclusivamente al heredero civil, pero ambos contendientes reclamaban tal condición, por lo que a ambos les incumbía la carga de la prueba de su título; en el caso del procedimiento per sponsionem y en el formulario, en cambio, al no tener una posición cuasisimétrica ambos litigantes, solo al actor pertenece la carga de probar tal calidad de heres, al igual que al dominus ex iure Quiritium en la rei vindicatio. Al coheredero, que en consecuencia necesita reclamar una parte (pro parte), se le confiere una acción especial a la que se dedica el título 4 del libro 5 del Digesto (si pars hereditatis petatur):

2. También se hallan activamente legitimados a esta acción: el aerarium, a fin de reclamar los bona caduca ${ }^{35}$; aquel que haya adquirido del fisco tales bienes ${ }^{36}$; y el fideicomisario universal, a través de la acción concedida en via utilis denominada hereditatis petitio fideicommisaria ${ }^{37}$.

3. En época clásica avanzada también se extenderá la legitimación al bonorum possessor mediante la llamada hereditatis petitio possessoria, presente en el edicto

${ }^{31}$ Paul. D. 5, 3, 4; 5, 3, 9; Gai. D. 5, 3, 10 pr.; Ulp. D. 5, 4, 1, 1

${ }^{32}$ Paul. D. 5, 3, 4; Gai. D. 5, 3, 41 pr.; Ulp. D. 12, 2, 11, 3. Frutos: Pap. D. 5, 3, 51, 1; Afr. D. 5, 3, 56; CI. 3, 31, 1 y 2 (M. Aur., 170). Lit. al respecto: KASER, Max, Nochmals über Besitz, cit. (n. 19), p. 114 n. 131; LuCHeTt, Giovanni, I primi due libri del commentario di Paolo "ad edictum". Parte seconda, en Studi Martini (Milano, 2009), pp. 518 ss.

${ }^{33}$ Cels. en Ulp. D. 5, 3, 18, 1. Sobre ello, véase TalamanCA, Mario, Studi sulla legitimazione passiva alla hereditatis petitio (Milano, 1956), pp. 42 s. y n. 109; SACCONI, Giuseppina, La "pluris petitio" nel processo formulare: contributo allo studio dll'oggetto del processo (Milano, 1977), pp. $24 \mathrm{~s}$.

${ }^{34}$ PS. 1, 13b, 6 = Cons. 6, 5a; Gai. D. 5, 3, 1; Iul. D. 12, 2, 12. Véase al respecto: Kaser, Max, RPR., I, p. 735; SelB, Walter, cit. (n. 21), p. 544; De LA RosA, Pelayo, cit. (n. 5), p. 1261; Casinos Mora, Francisco Javier, De Hereditatis, cit. (n. 5), pp. 159 s.

${ }^{35}$ Ulp. D. 5, 3, 20, 6-7, v. infra $\$$ V. 3 y n. 77.

${ }^{36}$ Iul. D. 5, 3, 54.

${ }^{37}$ D. 5, 6. Cfr. al respecto, Quadrato, Renato, voz Petizione, cit. (n. 3), p. 615. El tema requiere de una investigación más profunda. 
pretorio $^{38}$ y a la que el Digesto dedica un título ${ }^{39}$, cuyas sospechas de interpolación parecen hoy descartadas ${ }^{40}$. La progresiva equiparación de la bonorum possessio a la hereditas condujo a la jurisprudencia clásica a tratar de asegurar al bonorum possessor un medio de defensa adecuado, para el que el interdictum quorum bonorum no era idóneo, dada su limitación a la primera adquisición de la posesión de los bienes hereditarios (pero no a su recuperación) y su reserva para los corpora (y no, por tanto, los iura). En consecuencia, se admitió que el uso de la petitio hereditatis por el bonorum possessor, con las necesarias adaptaciones, sin perjuicio de la conservación del interdictum en su forma tradicional, dada su mayor agilidad procedimental y su efecto inversor de la carga de la prueba en beneficio del possessor en caso de litigio por la titularidad de la herencia ${ }^{41}$.

\section{LEGITIMACIÓN PASIVA}

1. La legitimación pasiva es muy amplia y, además, se trata de una de las cuestiones más controvertidas en relación con el régimen de esta figura ${ }^{42}$. En principio, el legitimado pasivo para la acción es el actual poseedor de toda la herencia o alguna cosa hereditaria singular ${ }^{43}$, o sus subrogados ${ }^{44}$. No tiene por qué ser una cosa corporal, sino que también puede tratarse de una res incorporalis (possessio iuris $^{45}$. En cuanto al tiempo de la posesión, hubo una discusión entre las escuelas

${ }^{38}$ Arg. ex Ulp. D. 5, 6, 1; cfr. Ulp. D. 5, 5, 1-2; schol. 1 a Bas. 42, 2, 11; 42, 2, 12 y schol. 1 a. h. l. Sobre su hipotética formula, véase Quadrato, Renato, Hereditatis Petitio Possessoria (Napoli, 1972), pp. 55 ss., 65 ss., 100 s.

${ }^{39}$ D. 5,5 .

${ }^{40}$ Iul. D. 37, 4, 13 pr.; Ulp. D. 37, 10, 3, 13; Hermog. D. 37, 10, 15. Lit. sobre el tema: fundamental, Quadrato, Renato, Hereditatis, cit. (n. 38), pp. 33 ss. y pass.; Él mismo, voz Petizione, cit. (n. 3), pp. 615 s.; además, KASER, MAX, RPR., II, p. 612 (pero cfr. RPR., I, p. 740 y n. 52 con lit.); Talamanca, Istituzioni, cit. (n. 8), p. 705; Müller-Ehlen, Martina, cit. (n. 19), pp. 4 n. 1, 29 nt. 53; Casinos Mora, De Hereditatis, cit. (n. 5), pp. 160 ss.; escéptico, LoNGO, Gianetto, rec. a Quadrato, Hereditatis petitio possessoria (1972), en Iura, 23 (1972), pp. 271 ss.; De la Rosa, Pelayo, cit. (n. 5), pp. 1261 s.; Selb, Walter, cit. (n. 21), p. 547; D’Ors, Álvaro, cit. (n. 13), pp. 320 s.

${ }^{41}$ Cfr. Gai. 3, 34; PS. 4, 8, 5 = Coll. 16, 3, 5. Lit.: Quadrato, Renato, Hereditatis, cit. (n. 38), pp. 73 ss.; Casinos Mora, Francisco Javier, De Hereditatis, cit. (n. 5), p. 163.

${ }^{42}$ Lit.: KASER, Max, RPR., I, pp. 735 s. (con amplia lit. en n. 5); Él MISMO, RPR., II, p. 546; Él Mismo, Pro herede vel pro possessore, en Studi Biscardi (Milano, 1982), II, pp. 221 ss.; SElB, Walter, cit. (n. 21), pp. 544 s.; Quadrato, Renato, voz Petizione, cit. (n. 3), pp. 612 ss.; DE LA Rosa, Pelayo, cit. (n. 5), pp. 1257 ss.; ANdrÉS SANTos, Francisco Javier, Subrogación, cit. (n. 14), pp. 54 ss.; ÉL MISMO, Claves romanistas de la legitimación pasiva en la acción de petición de herencia, en Actas del III Congreso Iberoamericano de Derecho romano (León, 1998), pp. 27 ss.; Müller-Ehlen, Martina, cit. (n. 19), p. 4; Casinos Mora, Francisco Javier, De Hereditatis, cit. (n. 5), pp. 163 ss.

${ }^{43}$ Paul. D. 5, 3, 4; 20, 4, 16 ; Ulp. D. 5, 3, 9; Gai. D. 5, 3, 10 pr.

${ }^{44}$ Ulp. D. 5, 3, 9; 5, 3, 16, 1-2, 5; 5, 3, 18 pr.; 5, 3, 31 pr.; 5, 4, 1, 1; Gai. D. 29, 4, 16 et al. Al respecto, véase ANDrÉs SANTOS, Francisco Javier, Subrogación, cit. (n. 14), pp. 54 ss.; además, cfr. supra $\$$ II 2 e infra $\$$ V. 4 a) y b). 4.2.

${ }^{45}$ Paul. D. 5, 3, 9; 5, 3, 13, 15; 5, 3, 18, 1; Iul. en Ulp. D. 5, 3,16, 4 y 7; Iul. en Paul. 20 D. 5, 3, 34, 1; Iul. en Gai. D. 5, 3, 35; 5, 4, 1, 1; Pap. 5, 4, 10; cfr. Lab. en Ulp. 39 ed. D. 
semejante a la que se dio para la rei vindicatio: para los proculeyanos es preciso que el demandado posea en el momento de la sentencia; para los sabinianos, en el de la litis contestatio ${ }^{46}$.

2. Pero, en cualquier caso, siempre es necesario que el demandado posea pro herede o pro possessore ${ }^{47}$. Posee pro herede el que cree ser heredero y no lo es, tenga o no título de heredero, con buena o mala fe, incluido el bonorum possessor ${ }^{48}$. En la época en que se tramitaba por la legis actio sacramento in rem, solo resultaba posible ejercitar la acción contra quien afirmara ser también heres a través de una contravindicatio; no cabía distinguir, por tanto, entre quienes poseyeran a título de heredero y quienes lo hicieran sin él, dado que ambas partes tenían que pronunciar idénticos certa verba y probar ambos sus alegaciones (véase más arriba en el texto sub $₫$ III. 1). En los tipos procedimentales posteriores, en principio solo se permitió asimismo entablar la acción contra el possessor pro herede, puesto que, si el demandado no invocaba ninguna clase de título para poseer los bienes hereditarios, se denegaba la acción, adjudicándose la posesión directamente al demandante, sin necesidad de prueba alguna de su título, a través del interdictum quam hereditatem. Solo a inicios de la época clásica se admitió el desarrollo del litigio contra el possessor pro possessore $e^{49}$. Para determinar la condición del poseedor demandado, no está claro el criterio seguido por los juristas, si uno de carácter procesal o uno sustantivo ${ }^{50}$. En el primer caso (interrogatio in iure), ante la pregunta

37, 1, 3, 1 et al. Categoría clásica, pese a las sospechas de itp.: véase KASER, Max, RPR., I, pp. 736 s. y n. 19; ÉL MISMO, RPR., II, p. 256; ÉL MISMO, Pro herede, cit. (n. 42), pp. 257 ss.; ÉL Mismo, Controversiam, cit. (n. 11), pp. 215 ss., 262 ss.; Calonge Matellanes, Alfredo, Los “iuris possessores" legitimados pasivos a la "hereditatis petitio", en Estudios Álvarez Suárez (Madrid, 1978), pp. 29 ss.; Quadrato, Renato, Hereditatis, cit. (n. 38), pp. 74 ss.; Él mismo, voz Petizione, cit. (n. 3), p. 612; Talamanca, Istituzioni, cit. (n. 8), p. 705; De la Rosa, Pelayo, cit. (n. 5), p. 1261; SELB, Walter, cit. (n. 21), p. 545 y n. 6; GuZMÁN BRITO, Alejandro, Derecho privado romano (Santiago de Chile, 1996), II, p. 567; D’Ors, Álvaro, cit. (n. 13), pp. 332, 337 n. 8; ANDrÉs SAntos, Francisco Javier, Subrogación, cit. (n. 14), pp. 56 s., 61 ss.; Müller-Ehlen, Martina, cit. (n. 19), pp. 7 s., 231 s. y n. 41, 253 ss.; Solidoro MARUotTi, Laura, La tutela del possesso in età costantiniana (Napoli, 1998), p. 324; Casinos Mora, Francisco Javier, De Hereditatis, cit. (n. 5), pp. 81 s., 164, 171 ss.; GonZÁlez RoldÁN, Yuri, Il senatoconsulto cit. (n. 19), pp. 122 s. y n. 38; Babusiaux, Ulrike, Papinians “Quaestiones”. Zur rethorischen Methode eines spätklassischen Juristen (München, 2011), pp. 228 s. Sobre el deudor hereditario, véase infra 4.

${ }^{46}$ Ulp. D. 5, 3, 18, 1. Véase al respecto, KASER, RPR., I, p. 736 y n. 14.

${ }^{47}$ Ulp. D. 5, 3, 9; 5, 3, 13 pr.-1/3 y 8; Pap. D. 5, 4, 10; CI. 3, 28, 1 (Sev.-Ant., 193); 3, 31, 7 (Diocl., 294); 7, 34, 4 (Diocl., 293); et al.; cfr. Gai. D. 29, 4, 16. Al respecto, véase, fundamentalmente, KaSER, Max, Pro herede, cit. (n. 42), pp. 221 ss.; más lit. supra nn. 42 y 49.

${ }^{48}$ Arrian.-Proc. en Ulp. D. 5, 3, 11 pr.; Gai. 2, 52 (usucapio pro herede); Gai. D. 29, 4, 16 (hereditario nomine possideat); Inst. Iust. 4, 15, 3 (pero cfr. Theoph., Par., h. 1.). Sobre la influencia del SC “Iuventianum”, véase infra $\$$ V.4. Lit. sobre el tema: KasER, Pro herede, cit. (n. 42), pp. 225 ss., 248 s.; Talamanca, Mario, Istituzioni, cit. (n. 8), p. 703; Müller-Ehlen, Martina, cit. (n. 19), pp. 13 s. n. 40 (con más lit.)

${ }^{49}$ Kaser, Max, RPR., I, p. 736; Él Mismo, Pro herede, cit. (n. 56), p. 228.

${ }^{50}$ Talamanca, Mario, Studi, cit. (n. 33), pp. 2 ss.; ÉL MISMO, Osservazioni sulla legitimazione passiva alle "actiones in rem", en Studi Cagliari, 43 (1964), pp. 178 ss.; KASER, Pro herede, cit. (n. 42), pp. 229 s.; Müller-Ehlen, Martina, cit. (n. 19), pp. 13 s. n. 40; Casinos Mora, Francisco Javier, De Hereditatis, cit. (n. 5), pp. 165 ss. 
del actor "cur possides" ("por qué posees"), si el interrogado responde "quia heres sum" ("porque soy heredero"), queda inmediatamente legitimado para soportar la acción, aun cuando sepa que no es heredero y, en consecuencia, esté de mala fe $\mathrm{e}^{51}$. Según el segundo criterio, es el título de posesión el determinante de la condición del poseedor y, por tanto, la legitimación pasiva para esta acción ${ }^{52}$.

3. Poseedor pro possessore es el que, teniendo en su poder la herencia, o una parte de ella o cosas hereditarias singulares, no ostenta legítimamente el título de heredero, pero tampoco de alguna otra causa para tener ${ }^{53}$. En general, poseen pro possessore todos aquellos que ocupan de cualquier modo una herencia en todo o en parte, o cosas hereditarias, sin causa possessionis típica, sabiendo que no son herederos ${ }^{54}$; típicamente posee de esta manera el que hurta y el que roba (fur y praedo $)^{55}$. En la interrogatio in iure sobre "cur possides", estas personas no responden sino "quia possideo" ("porque poseo") ${ }^{56}$. En cualquier caso, en época clásica los efectos de esta distinción son inapreciables y ambos tipos de poseedor de la hereditas son tratados de modo semejante y, sobre todo a partir del SC. "Iuventianum" (véase más abajo en el texto), la oposición verdaderamente significativa será la de possessor bonae fidei /possessor malae fidei.

4. Está también pasivamente legitimado para la acción el deudor hereditario (que se considera un possessor iuris), esto es, el que lo fue del causante ${ }^{57}$; y también el deudor de la herencia, es decir, el que asumió la deuda durante el periodo de hereditas iacens (v. gr. por haber prometido al servus hereditarius) ${ }^{58}$, en particular,

${ }^{51}$ Ulp. D. 5, 3, 12 (arg. a contrario); CTh. 11, 39, 12 (Arcad.-Hon., 396/402 = CI. 3, 31, 11). La equiparación entre possessor pro herede y bonae fidei possessor es bizantina: Theoph., Par. 4, 15, 3 (cfr. Inst. Iust. h. l.). Lit. sobre el tema: KASER, Max, Die Passivlegitimation, cit. (n. 8), pp. 93 ss.; Él mismo, RPR., I, p. 736 y n. 9; Él mismo, RPR., II, p. 546 y n. 15; Él mismo, Pro herede, cit. (n. 42), pp. 235 ss., 254 ss. (lucha de escuelas); contra, Talamanca, Mario, Studi, cit. (n. 33), pp. 7 ss.; Quadrato, Renato, voz Petizione, cit. (n. 3), p. 613; Talamanca, Mario, Istituzioni, cit. (n. 8), p. 703; SELB, Walter, cit. (n. 21), p. 545; Spengler, Hans-Dieter; Studien zur interrogatio in iure (München, 1994), pp. 150 ss.; Casinos Mora, De Hereditatis, cit. (n. 5), pp. 141 ss.

${ }_{52}$ Gai. 4, 144; Ulp. D. 5, 3, 12; cfr. Ulp. D. 4, 2, 14, 2; 5, 3, 3/8/11/13, 1/16, 4; Pomp. D. 35, 1, 110; 41, 6, 3; Iul. D. 41, 3, 33, 1. Véase al respecto, KASER, Max, RPR., I, p. 740 y n. 55 (con lit.); Él MISMO, Pro herede, cit. (n. 42), pp. 231 y n. 40, 237 ss.; Quadrato, Renato, Hereditatis, cit. (n. 38), pp. 75 s., 85 ss; Talamanca, Mario, Studi, cit. (n. 33), pp. 19 ss.; ÉL MISMO, Istituzioni, cit. (n. 8), p. 703; SELB, Walter, cit. (n. 21), p. 545 y n. 5 ; CASINOS MorA, De Hereditatis, cit. (n. 5), pp. 166 ss.; además, véase infra n. 54.

${ }^{53}$ Por todos, véase Kaser, Max, RPR., I, pp. 735 s.; Él Mismo, Pro herede, cit. (n. 56), pp. 253 ss.

${ }^{54}$ Gai. 4, 144 (int. quorum bonorum); Ulp. D. 5, 3, 11 pr.-1; Iul. en Ulp. D. 5, 3, 16, 4; a sensu contrario Gai. D. 29, 4, 16 (hereditario nomine possideat). Véase lit. al respecto supra en n. 52.

${ }^{55}$ Ulp. D. 5, 3, 11, 1/13 pr.; Nerat. en Ulp. D. 5, 3, 13, 3.

${ }^{56}$ Ulp. D. 5, 3, 12.

${ }^{57}$ Ulp. D. 5, 3, 13, 15; cfr. Ulp. D. 5, 3, 42; Pap. D. 5, 4, 10. Lit. al respecto: Kaser, Max, RPR., I, p. 737 y n. 17; Él mismo, Pro herede, cit. (n. 42), pp. 258 ss.; Calonge Matellanes, Alfredo, cit. (n. 45), pp. 33 y n. 16 (con lit.), 42 s.; Quadrato, Renato, voz Petizione, cit. (n. 3), p. 614; BuRdese, Alberto, rec. de L. Solidoro Maruotti, La tutela del possesso in età costantiniana (1998), en Recensioni e commenti: sessant'anni di letture romanistiche (Padova, 2009), p. 304.

${ }^{58}$ Paul. D. 5, 3, 14. 
el gestor de las cosas hereditarias durante dicho estado ${ }^{59}$; y el que, durante ese lapso temporal, cometió algún delito que lo deje obligado a una pena que deba recaer a favor de la herencia ${ }^{60}$.

5. Hay otras hipótesis en que se admite el ejercicio de la acción contra quien nihil possidet (fictus possessor), como también sucede en la rei vindicatio, en virtud del principio (fictio iuris) dolus pro possessione est ${ }^{61}$. Tal es el supuesto de quien se ofrece como demandado a la acción (oblatio liti), fingiéndose poseedor, a fin de permitir que otro consolide la usucapión de los bienes hereditarios ${ }^{62}$, así como quien deja dolosamente de poseer (qui dolo desierit possidere) para evitar los perjuicios de la acción ${ }^{63}$.

6. Por el contrario, en contra del que poseyera la totalidad de la herencia o una parte de ella por otra causa (pro emptore, pro donato, pro dote, etc.) no se da en principio la petitio hereditatis ordinaria. Sin embargo, en determinados supuestos (caso del adquirente de la herencia parvo pretio, del fideicomisario universal en idéntica situación y del marido poseedor de la herencia pro dote), algunos juristas la dan como utilis ${ }^{64}$.

${ }^{59}$ Ulp. D. 5, 3, 16, 3.

${ }^{60}$ Gai. D. 5, 3, 15; Paul. D. 5, 3, 24; Iul. D. 10, 2, 51, 1.

${ }^{61}$ Ulp. D. 5, 3, 27 pr.; D. 50, 17, 157, 1 et al.; Gai. D. 5, 3.41 pr.; Paul. D. 35, 3, 4, 2; 50, 17, 131; cfr. Ulp. D. 6, 1, 22; Paul. D. 50, 17, 131. Véase sobre el tema: KASER, RPR., I, pp. 433 n. 15, 736 n. 14; ÉL MISMO, RPR., II, p. 548; ÉL MISMO, Nochmals über Besitz, cit. (n. 19), pp. 106 ss., 126 ss.; KASER, Max - HACKL, Karl, cit. (n. 9), p. 252; MÜller-Ehlen, Martina, cit. (n. 19), p. 324 y nt. 40; GonZÁlez RoldÁn, Yuri, El principio "dolus pro possessione est" en la perspectiva del senadoconsulto Juvenciano, en Revista de Investigaciones Jurídicas, 27 (México, 2003), pp. 309 ss. Sobre el SC “Iuventianum” en este punto, véase infra $\$$ V. 4 y nn. 81 y 82.

${ }^{62}$ Gai. D. 4, 3, 39; Cels. en Ulp. D. 5, 3, 13, 13; Cels. D. 5, 3, 45. Véase al respecto, KASER, Max, RPR., I, p. 737; Él MISMO, RPR., II, p. 546 y n. 17; Él mISMO, Nochmals über Besitz, cit. (n. 19), pp. 142 s.; Él mismo, Controversiam, cit. (n. 11), pp. 234 ss.; SCHIPANI, Sandro, cit. (n. 21), pp. 196 ss.; Talamanca, Mario, Note sulla "oblatio liti", en Spruit, Jan E. (ed.), Maior viginti quinque annis. Essays in Commemoration of the Sixth Lustrum of the Institute for Legal History of the University of Utrecht (Assen, 1979), pp. 169 ss.; AlbanesE, "Rei vindicationi se offerre" e "actio de dolo", en AUP., 33 (1972), pp. 404 ss.; Quadrato, Renato, voz Petizione, cit. (n. 3), p. 614 y n. 64; MÜller-Ehlen, Martina, cit. (n. 19), pp. 316 s.; GonZÁlez RoldÁN, Yuri, El principio “dolus pro possessione est", cit. (n. 86), pp. 336 ss.; CASINOS MorA, Francisco Javier, De Hereditatis, cit. (n. 5), pp. 174 ss.

${ }^{63}$ Ulp. D. 5, 3, 13, 14; 5, 3, 20, 6c; 5, 3, 25, 2 y 7; cfr. Ulp. inst. fr. Vind. 4 (FIRA, II, p. 306). Sobre el tema, véase KaSER, Max, RPR., I, p. 737; Él MISMO, RPR., II, p. 546 y n. 18; Quadrato, Renato, voz Petizione, cit. (n. 3), p. 614; De la Rosa, Pelayo, cit. (n. 5), p. 1260; Andrés Santos, Francisco Javier, Subrogación, cit. (n. 14), pp. 58 y n. 49, 85 ss. y n. 162, 126 n. 287; MÜller-Ehlen, Martina, cit. (n. 19), pp. 157, 276 s., 299 s., 304 ss., 355, 382 s.; GonZÁlez Roldán, Yuri, El principio "dolus pro possessione", cit. (n. 61), pp. 348 ss.; Casinos Mora, Francisco Javier, De Hereditatis, cit. (n. 5), p. 175.

${ }^{64}$ Ulp. D. 5, 3, 13, 4-5 y 8-10. Lit. al respecto: KaSER, Max, RPR., I, p. 736; ÉL MISMO, RPR., II, p. 546; HaCKL, Karl, "Praeiudicium" im klassischen römischen Recht (Salzburg, 1975), pp. 77 ss., 90, 94; Valiño, Emilio, Actiones utiles (Pamplona, 1974), pp. 157 ss.; Calonge Matellanes, Alfredo, cit. (n. 45), p. 41; Quadrato, Renato, voz Petizione, cit. (n. 3), p. 614; KuIngenberg, Georg, Das "Edictum divi Marci de rebus alienis a fisco distractis", en RIDA., 34 (1987), pp. 190 ss. 


\section{Responsabilidad del poseedor de la herencia. El SC. "IUVENTIANUM"}

1. La restitución que deberá realizar el poseedor hereditario que resulte condenado por la acción comprenderá todas las res hereditariae, sean corporales o derechos, si el actor es heredero universal ${ }^{65}$; si no es tal, comprenderá solo la parte que le corresponda de ellas ${ }^{66}$.

2. El poseedor de la herencia o de cosa hereditaria es responsable frente al heredero de los deterioros de la herencia (v. gr. no cobrar las deudas) causados por dolus y culpa ${ }^{67}$ : en tal caso, en la restitución deberán incluirse todas las pérdidas y menoscabos sufridos por los bienes hereditarios ${ }^{68}$, así como las ganancias deshonro$\mathrm{sas}^{69}$. Como regla general, se establece que el poseedor de mala fe no puede obtener mejor trato que el de buena $\mathrm{fe}^{70} \mathrm{y}$ se presume que mala fides superveniens nocet ${ }^{71}$. Conforme al concepto del restituere, al igual que en la rei vindicatio, después de la litis contestatio el actor tiene derecho a que se le restituya la herencia tal como si la hubiera recibido en ese momento, junto con las adquisiciones posteriores ${ }^{72}$; a partir de la litis contestatio (o post controversiam motam), todos los poseedores son considerados de mala $\mathrm{fe}^{73}$.

3. Toda esta materia fue objeto de una remodelación a través de un senadoconsulto del año 129 d.C., conocido como SC "Iuventianum" por haber sido emitido siendo cónsul el jurista Publio Juvencio Celso (el verdadero nombre del decreto senatorial debió de ser, por tanto, $S C$ " $Q$. Iulio Balbo et P. Iuventio Celso consulibus factum" $)^{74}$, cuyo pensamiento parece haber influido en su contenido, y

${ }^{65}$ Ulp. D. 5, 3, 18, 2; cfr. Paul. D. 5, 3, 19, 3.

${ }^{66}$ Gai. D. 5, 3, 10.

${ }^{67}$ Dolus: Ulp. D. 5, 3, 20, 6; 5, 3, 25, 7-10; culpa: Paul. D. 5, 3, 19, 2; Ulp. D. 5, 3, 25, 2; 5, 3, 31, 3; cfr. Pap. D. 5, 3, 49. Lit. al respecto: KASER, Max, RPR., I 738; ÉL MISMO, RPR., II, p. 547 y n. 23; Müller-Ehlen, Martina, cit. (n. 19), pp. 323 ss.

${ }^{68}$ Paul. D. 5, 3, 36, 2; Iul. D. 5, 3, 54, 2; Müller-Ehlen, Martina, cit. (n. 19), pp. 227 ss., 247 ss., 325 s.

${ }^{69}$ Hermog. D. 5, 3, 52.

${ }^{70}$ Paul. D. 5, 3, 36, 3.

${ }^{71}$ Ulp. D. 5, 3, 25, 5. Con relación a la usucapio pro herede, véase infra n. 75.

${ }^{72}$ Paul. D. 5, 3, 40 pr. Véase lit. al respecto supra nn. 32 y 33. Caso de daños a la masa hereditaria post litem contestatam, hay disputa de escuelas: Paul. D. 5, 3, 40; cfr. Ulp. D. 5, 3, 27 pr; Gai. D. 5, 3, 41 pr.; Nerat. D. 5, 3, 57; Paul. D. 35, 3, 4, 2 itp. Véase al respecto: Selb, Walter, cit. (n. 21), p. 546 y n. 10; MülLER-Ehlen, Martina, cit. (n. 19), pp. 376 ss.

${ }^{73}$ Ulp. D. 5, 3, 20, 11; 5, 3, 25, 7; D. 5, 3, 31, 3. Véase al respecto: KaSER, RPR., I, pp. 518,738 n. 35.

${ }^{74}$ Texto del SC: Ulp. D. 5, 3, 20, 6-6d, al que sigue el comentario de Ulpiano. Lit. sobre el tema: ahora, fundamental, GonZÁlez RoldÁn, Yuri, Il senatoconsulto, cit. (n. 19), pp. 197 ss.; Él MISMO, Il senatoconsulto, cit. (n. 21), pass.; además, KASER, Max, RPR., I, p. 739 y nt. 41 (con lit. anterior); ÉL MISMO, Nochmals über Besitz, cit. (n. 19), pp. 126 ss.; KASER, Max - HACKL, Karl, cit. (n. 9), p. 297 y n. 13; Quadrato, Renato, voz Petizione, cit. (n. 3), p. 614 y n. 72; DE la Rosa, Pelayo, cit. (n. 5), pp. 1258 ss.; Welle, Arno, In universalibus, cit. (n. 21), pp. 22 s.; Andrés Santos, Francisco Javier, Subrogación, cit. (n. 14), pp. 68 ss., 78 ss.; Müller-Ehlen, Martina, cit. (n. 19), pp. 46 ss., 316 ss. y pass.; CASINOS MORA, Francisco Javier, La repercusión del senadoconsulto Juvenciano en materia de reclamación de herencia, en REHJ., 23 (2001), pp. 53 ss.; ÉL MISMO, De Hereditatis, cit. (n. 5), pp. 125 ss. 
que fue consecuencia de una previa oratio principis del emperador Adriano (oratio Hadriani $)^{75}$. El SC tuvo su origen en una hereditatis petitio fiscal entablada por el aerarium $^{76}$ contra ciertos sujetos que, creyéndose herederos, habían llevado a cabo ventas de bienes hereditarios que correspondían al tesoro público en concepto de bona caduca, de conformidad con lo establecido por las leyes caducarias de Augusto. El SC estableció un régimen para el caso de dichos bona caduca dejados de poseer por el demandado antes de haber recaído la litis contestatio en la vindicatio caducorum ${ }^{77}$. Esa regulación pronto, tal vez desde el primer momento, se extendió a otros supuestos distintos de hereditatis petitiones fiscales y de entidades públicas (civitates) $)^{78}$, así como a las de los privados en general ${ }^{79}$, lo que dio lugar a una j u ve n c i a n i z a c i ó n de la acción hereditaria ${ }^{80}$.

4. El SC fue dictado principalmente con el fin de regular los problemas relativos a la enajenación de bienes hereditarios, el dolus praeteritus del poseedor y los frutos de la herencia ${ }^{81}$, pero su regulación fue mucho más lejos, si bien no dejaba de recoger muchos principios ya vigentes con anterioridad ${ }^{82}$. En cualquier caso,

${ }^{75}$ Texto parcial: Paul. D. 5, 3, 22; $c f r$. D. 5, 3, 40 pr.; CI. 3, 31, 1 pr. (M. Aurel., 170). Lit. al respecto: cf. nota anterior y, sobre todo, GonZALEZ ROLDÁN, Yuri, Il senatoconsulto, cit (n. 19), pp. 373 ss. La reforma guarda relación con la supresión de la usucapio pro herede lucrativa (Gai. $2,57)$ y con un rescripto adrianeo sobre la repetición de los legados pagados por el vendedor vencido (Ulp. D. 12, 6, 2/4). Lit. sobre ello en D'Ors, Álvaro, cit (n. 13), p. 336 nt. 2.

${ }^{76}$ Ulp. D. 5, 3, 20, 6a/6d: [fisco] <aerario > (probablemente ya clásico: cfr. PROVERA, Giuseppe, La "vindicatio caducorum": contributo allo studio del processo fiscale romano [Torino, 1964], p. 34 n. 35). Sobre el tema, véase ahora GonZÁlez Roldán, Yuri, "Senatusconsultum Iuventianum". Apuntes para la reconstrucción de un litigio fiscal en la época de Adriano, en Revista de Investigaciones Jurídicas, 22 (México, 1998), pp. 139 ss.; ÉL MISMO, La apelación frente al senado en la edad de Adriano. Una teoría con base en D. 5.3.20.6, en Revista de Investigaciones Jurídicas, 25 (México, 2001), pp. 229. ss.; Él MISMO, Il senatoconsulto, cit. (n. 19), pp. 31 ss., 305 ss., 396 ss.

${ }^{77}$ Casinos Mora, Francisco Javier, De Hereditatis, cit. (n. 5), p. 56; González Roldán, Yuri, Il senatoconsulto, cit. (n. 19), pp. 56 ss.

${ }^{78}$ Ulp. D. 5, 3, 20, 8. Sobre este punto, véase GonZAlez RoldÁn, Il senatoconsulto, cit. (n. 19), pp. 339 ss.

${ }^{79}$ Ulp. D. 5, 3, 20, 6/9; CI. 3, 31, 1 pr. (M. Aurel., 170). Sobre el momento de su extensión, véase KASER, Die Passivlegitimation, cit. (n. 8), p. 104; ÉL MISMO, Nochmals über Besitz, cit. (n. 19), p. 115; Quadrato, Renato, voz Petizione, cit. (n. 3), p. 614 n. 72; Selb, Walter, cit. (n. 21), pp. 545 s. nt. 9.; Welle, Arno, In universalibus, cit. (n. 21), p. 28; Andrés Santos, Francisco Javier, Subrogación, cit. (n. 14), pp. 80 ss.; Müller-Ehlen, cit. (n. 19), pp. 46 ss.; CASINOS Mora, Francisco Javier, De Hereditatis, cit. (n. 5), p. 129; GonZÁLEZ RoldÁn, Il senatoconsulto, cit. (n. 19), pp. 357 ss.

${ }^{80}$ Véase sobre esto: KaSer, Die Passivlegitimation, cit. (n. 8), pp. 116 ss.; TalamanCa, Mario, Istituzioni, cit. (n. 8), p. 704. Sobre su influencia en la rei vindicatio, cfr. Paul. D. 6, 1, 27, 3 itp?. Lit. al respecto: KASER, Max, Nochmals über Besitz, cit. (n. 19), pp. 112 s.; Díaz BAUTISTA, Antonio, La buona fede nel Senatoconsulto Giuvenziano, en Il ruolo della buona fede oggettiva nell'esperienza giuridica storica e contemporanea: Atti del Convegno Internazionale di Studi in onore di Alberto Burdese (Padova, Venezia, Treviso, 14-15-16 gingno 2001) (Padova, 2003), I, pp. 501 ss.; GonzÁlez RoldÁn, Yuri, Il senatusconsulto, cit. (n. 19), pp. 216 ss.; contra Müller-EHLen, cit. (n. 19), pp. 346 ss.

${ }^{81}$ Ulp. D. 5, 3, 20, 6. Lit. al respecto: Kaser, Max, RPR., I, p. 736 n. 15, y la citada en n. 105.

${ }^{82}$ Así, KASER, Max, RPR., I, pp. 736 n. 15, 737, 738 nt. 26; Él MISMO, RPR., II, pp. 546 n. 18 y 20, 547 n. 23; Schipani, Sandro, cit. (n. 21), pp. 180 ss.; Quadrato, Renato, voz 
el SC introdujo dos innovaciones importantes en relación con la valoración de la responsabilidad del poseedor hereditario demandado por la acción ${ }^{83}$. En primer lugar, contempla la posibilidad de reclamar los precios obtenidos de la venta de los bienes hereditarios, a pesar de que estos ya no existiesen en poder del vendedor y se hubiesen perdido tanto para él como para el heredero ${ }^{84}$. En segundo lugar, se establece una distinción más acusada en el trato que se dispensa al demandado con la hereditatis petitio según su condición de poseedor de buena fe (iustus possessor) o de mala fe (praedo), y la responsabilidad derivada de su condena en el juicio se articula a partir de la regla básica del enriquecimiento obtenido por el poseedor en su gestión de los bienes hereditarios ("in quo locupletiores facti sunt") ${ }^{85}$. De acuerdo con esta distinción, se fijan los límites de la responsabilidad exigible al demandado en los siguientes términos ${ }^{86}$ :

a) Poseedor de buena fe. La restitución se limita en relación con el enriquecimiento solo al conservado en la actualidad, de modo que no comprende la parte de la herencia consumida o donada ${ }^{87}$; respecto a los créditos no satisfechos, basta con que los ceda al actor a riesgo de este ${ }^{88}$. En cuanto a las cosas hereditarias vendidas ante petitam hereditatem, solo comprende el precio obtenido y no los intereses devengados, pero, si no lo hubiera percibido, basta con ceder la acción correspondiente $^{89}$; en caso de venta y posterior readquisición, incluye los bienes adquiridos y solo la parte del precio cobrado que se conserve ${ }^{90}$. Los frutos se limitan

Petizione, cit. (n. 3), p. 614 nt. 72; ANDRÉs SANTOS, Francisco Javier, Subrogación, cit. (n. 14), p. 87 nt. 165; Casinos Mora, Francisco Javier, De Hereditatis, cit. (n. 5), pp. 133 ss.; contra, Selb, Walter, cit. (n. 21), p. 545; De la RosA, Pelayo, cit. (n. 5), pp. 1260 s.; D’Ors, Álvaro, cit. (n. 13), p. 336 nt. 2; una discusión del problema puede verse en Müller-EHLEN, Martina, cit. (n. 19), p. 48 y pass.

${ }^{83}$ Casinos Mora, Francisco Javier, De Hereditatis, cit. (n. 5), pp. 132 ss.

${ }^{84}$ Anton. en Iul. D. 4, 2, 18; Ulp. D. 5, 3, 18 pr.; 5, 3, 23 pr.;5, 3, 25, 1; 5, 3, 33, 1. Lit. al respecto, Müller-Ehlen, Martina, cit. (n. 19), pp. 332 s., 348 ss., 363 ss.; GonZÁlez RoldÁn, Yuri, Il senatoconsulto, cit. (n. 19), pp. 110 ss. (con lit. en n. 8).

${ }^{85}$ Paul. D. 5, 3, 28. Véase al respecto, GonZÁlez Roldán, Yuri, Il senatoconsulto, cit. (n. 19), pp. $144,268 \mathrm{~s}$.

${ }^{86}$ Lit. sobre el tema: KASER, Max, RPR., I, p. 739; TALAMANCA, Mario, Istituzioni, cit. (n. 8), p. 704; Welle, Arno, In universalibus, cit. (n. 21), pp. 29 ss.; ANDrÉs Santos, Francisco Javier, Subrogación, cit. (n. 14), pp. 96 ss.; Müller-Ehlen, Martina, cit. (n. 19), pass.; Díaz Bautista, La buona fede, cit. (n. 111), pp. 494 ss.; CAsinos Mora, Francisco Javier, De Hereditatis, cit. (n. 5), pp. 132 ss., 151 ss.; GonZÁLEZ Roldán, Il senatoconsulto, cit. (n. 19), 107 ss.

${ }^{87}$ Ulp. D. 5, 3, 23 pr.; 5, 3, 25, 1; 5, 3, 11-17. Sobre el tema, véase MüLLER-EHLEN, Martina, cit. (n. 19), pp. 357 ss.; GONZÁleZ RoldÁn, Il senatoconsulto, cit. (n. 19), pp. 107 ss.

${ }^{88}$ Paul. D. 5, 3, 30. Véase al respecto, Müller-Ehlen, Martina, cit. (n. 19), pp. 226 ss., 294 ss

${ }^{89}$ Ulp. D. 5, 3, 20, 6a/b; 5, 3, 20, 15; 5, 3, 20, 17; 5, 3, 25; Paul. D. 5, 3, 24. Lit. al respecto: ANDrÉs SANTOS, Francisco Javier, Subrogación, cit. (n. 14), pp. 88 ss., 91 n. 177; GonZÁleZ ROLDÁN, Yuri, La subrogación del precio a las cosas hereditarias en la perspectiva del senadoconsulto Juvenciano, en Revista de Investigaciones Jurídicas, 28 (México, 2004), pp. 241 ss.; ÉL MISMO, Il senatoconsulto, cit. (n. 19), pp. 108 ss., 147.

${ }^{90}$ Paul. D. 5, 3, 23; Ulp. D. 5, 3, 24-25. Sobre el tema, véase: AndrÉs SANTOS, Francisco Javier, Subrogación, cit. (n. 14), pp. 93 ss.; GONZÁLEZ ROLDÁN, Il senatoconsulto, cit. (n. 19), pp. 127 ss. 
a los efectivamente percibidos, siempre que supongan un enriquecimiento para el poseedor ${ }^{91}$. Este tiene derecho a una exceptio doli para la deducción o reintegro de las impensas necesarias o útiles sobre la herencia producidas antes de la litis contestatio $^{92}$. En caso de deudas hereditarias, el poseedor puede imputar los pagos efectuados sin necesidad de prestar caución; si la deuda fuese a favor del mismo poseedor, puede deducirla por compensación ${ }^{93}$.

b) Poseedor de mala fe. En su caso se aplica sin limitación la regla del enriquecimiento, solo con ciertas correcciones. Debe restituir la totalidad del lucro obtenido por la venta de bienes hereditarios y asimismo sus intereses ${ }^{94}$ y su responsabilidad se extiende aun ante litem contestatam (dolus praeteritus) ${ }^{95}$. Si la venta se efectuó ante petitam hereditatem y hereditatis causa, puede el actor optar entre exigir la estimación de las cosas vendidas y sus frutos o el precio y los intereses generados post motam controversiam ${ }^{96}$. En cambio, si la venta fue sui causa, la restitución comprende las cosas mismas y sus frutos o, en su caso, su estimación arbitrio petitoris; e, igualmente, en caso de pérdida o disminución, su verum pretium ${ }^{97}$. Si hay readquisición de los bienes hereditarios, comprende tanto los bienes mismos como el lucro conseguido en el negocio ${ }^{98}$. Deben restituirse todos los frutos, incluso los fructus percipiend $\imath^{99}$. Las impensas necesarias o útiles no pueden deducirse o reintegrarse en derecho clásico, pero Justiniano admitió que se hiciera officio iudicis solo si se mantienen y la cosa resultó mejorada ${ }^{100}$. Pueden imputarse las deudas pagadas hereditatis causa, previa caución de defensa del actor, salvo que sean deudas a favor del mismo poseedor ${ }^{101}$.

${ }^{91}$ Ulp. D. 5, 3, 25, 4; Paul. D. 5, 3, 40, 1 . Sobre ello, véase: CARDilli, La nozione, cit. (n. 19), pp. 303 ss.; GonZÁlez RoldÁn, Yuri, La responsabilidad, cit. (n. 19), pp. 675 ss.; Il senatoconsulto, cit. (n. 19), pp. 251 ss.

${ }^{92}$ Paul. D. 5, 3, 38 itp.; Gai. D. 5, 3, 39, 1; Pap. D. 5, 3, 50, 1. Lit. al respecto: KASER, Max, $R P R$. I, p. 738, pero $c f r$. Él mismo, $R P R$., II, p. 547 y n. 25; GonZÁlez-PalenZuela Gallego, María Teresa, Las impensas en el derecho romano clásico (Cáceres, 1998), pp. 42, 111 ss., 223 ss., 241 s.; Müller-Ehlen, Martina, cit. (n. 19), pp. 177 ss., 428 ss.

${ }^{93}$ Ulp. D. 5, 3, 31 pr. y 2. Sobre legados, cfr. Gai. D. 5, 3, 17. Véase al respecto: MülLEREhlen, Martina, cit. (n. 19), pp. 386 ss.; GonZÁlez Roldán, Yuri, Il senatoconsulto, cit. (n. 19), pp. 133 s.

${ }_{94}^{4}$ Ulp. D. 5, 3, 20, 6; D. 5, 3, 23 (a contrario). Lit. al respecto: Andrés SANTOS, Francisco Javier, Subrogación, cit. (n. 14), pp. 91 n. 177, 96; GonZÁlez RoldÁn, Yuri, Il senatoconsulto, cit. (n. 19), pp. 127 ss.

${ }^{95}$ Ulp. D. 5, 3, 25, 7. Lit. sobre ello: Andrés SAnTos, Francisco Javier, Subrogación, cit. (n. 14), p. 86 y n. 163; GonZález RoldÁN, Yuri, El principio "dolus pro possessione", cit. (n. 62), pp. 305 ss.; ÉL MISMO, Il senatoconsulto, cit. (n. 19), pp. 203 ss.

${ }^{96}$ Ulp. D. 5, 3, 20, 12; cfr. D. 5, 3, 20, 2 (deudas hereditarias). Sobre ello, véase GonZÁLEZ RoldÁN, Il senatoconsulto, cit. (n. 19), pp. 94 ss., 104, 121, 161 ss.

${ }^{97}$ Ulp. D. 5, 3, 20, 2/12/21. Lit. al respecto: KASER, Nochmals über Besitz, cit. (n. 19), pp. 126 ss.; AndRÉs SANTOS, Francisco Javier, Subrogación, cit. (n. 14), pp. 91 n. 177, 96 s.

${ }^{98}$ Paul. D. 5, 3, 22. Lit.: como en n. 75.

${ }^{99}$ Ulp. D. 5, 3, 25, 4; 5, 3, 27 pr.-1; Paul. D. 5, 3, 40, 1; Inst. Iust. 4.17.2. Lit. sobre ello: KASER, RPR., II, p. 547 y n. 23.

${ }^{100}$ Paul. D. 5, 3, 38 itp.; Gai. D. 5, 3, 39, 1 (ius tollendi); cfr. Scaev. D. 5, 3, 58. Sobre el tema, véase GonZAlez-Palenzuela Gallego, Las impensas, cit. (n. 92), pp. 111 ss.

${ }^{101}$ Ulp. D. 5, 3, 31 pr.-1. Lit. sobre el tema: Mǘler-EhLEN, Martina, cit. (n. 19), pp. 110 


\section{Reflexiones conclusivas. Perspectivas}

1. Como ha podido observarse a la vista de las páginas que anteceden, la institución que es objeto de este breve estudio ofrece aún numerosos cabos sueltos que reclaman una investigación más profunda, a partir ya del hecho de que, a diferencia de lo que encontramos en el Derecho moderno, lo que podemos denominar "acción hereditaria" o "acción a petición de herencia" está lejos de presentar un aspecto unitario en el derecho romano clásico. Junto a la hereditatis petitio originaria, y que marca la pauta a las demás, aparecen, como consecuencia de la actividad del pretor, otras figuras alternativas y/o complementarias, como son la $h$. p. partiaria, la h. p. possessoria, la h. p. fideicommissaria y el interdictum quorum bonorum, las cuales, si bien adoptan básicamente la estructura de la acción originaria, exhiben también otros perfiles que las caracterizan, lo que da lugar a un panorama muy complejo y, en ciertos aspectos, contradictorio. En el derecho justinianeo, sin embargo, se observa una clara tendencia a la convergencia que prefigura lo que será el modelo de acción hereditaria del derecho moderno. Sin embargo, si bien la hereditatis petitio por antonomasia ha sido objeto, como hemos visto, de numerosas investigaciones monográficas ya desde la Pandectística -y aun del derecho común más antiguo ${ }^{102}$-, las otras figuras, en cambio, apenas han sido tocadas con alguna profundidad por parte de la romanística moderna (con excepción, quizá, de la hereditatis petitio possessoria, estudiada hace ya algún tiempo por Quadrato ${ }^{103}$ ). Todas ellas requerirían, pues, de una observación más detenida a partir de los avances en el conocimiento de la hereditatis petitio en general que hemos ido desgranando en estas páginas, y que aquí, por evidentes razones de espacio, no ha sido posible abordar.

2. Con independencia de esto, es decir, de una reconsideración general de la figura a la vista de los resultados de la crítica textual contrastados con las aportaciones de la tradición romanística en su conjunto, hay algunos aspectos concretos referidos al origen, la regulación clásica y la revisitación justinianea de la hereditatis petitio en los que existe cierta controversia en la doctrina romanista actual y que bien necesitarían de una cierta revisión crítica. De entre ellos podemos destacar, sobre todo, la propia ubicación dogmática de la petitio hereditatis en el interior del sistema de acciones romano-clásico, y en particular sus signos distintivos como acción universal, y las tensiones que ella ocasiona en el seno de la dicotomía actio in rem lactio in personam dentro del esquema clásico. La valoración del problema por los juristas clásicos y su recensio por parte de la jurisprudencia postclásica y los compiladores justinianeos sigue siendo un terreno escabroso para la doctrina romanista actual. Asimismo, otro problema conectado en gran medida con este es el del procedimiento a seguir para tramitar la reclamación, habida cuenta de la convivencia del viejo procedimiento per sponsionem y el modernizado procedimiento per formulam, así como la progresiva penetración de la cognitio extra ordinem, y

ss.; GonZÁlez RoldÁn, Yuri, Il senatoconsulto, cit. (n. 19), pp. 133 s.

${ }^{102}$ Véase Zimmermann, Edward, Beitrag zur Lehre der "hereditatis petitio", en Archiv für die Civilistische Praxis, 29 (1846), pp. 212 ss., y los allí citados.

${ }^{103}$ Quadrato, Renato, Hereditatis, cit. (n. 38). 
la dificultad para precisar cómo se produciría la elección entre uno u otro sistema (y, por consiguiente, el órgano judicial al que competería la resolución del litigio).

De entre los aspectos estructurales de la acción, sigue siendo un problema grave el de la determinación de la legitimación pasiva a esta acción, a pesar de los numerosos estudios dedicados a esta problemática ya al menos desde Lenel ${ }^{104}$, en particular con respecto a la controvertida cuestión de la possessio iuris como criterio de legitimación, y su carácter clásico o justinianeo. Es igualmente discutible la genuinidad clásica de la equiparación que aparece en las fuentes justinianeas entre possessor pro herede y possessor bonae fidei (y, por consiguiente, entre poss. possessor possessore y praedo). Cuestión que, por cierto, es extensible asimismo al régimen de la rei vindicatio, toda vez que, según la doctrina más autorizada ${ }^{105}$, esta distinción podría haber sido introducida en la reivindicatoria precisamente a partir de la hereditatis petitio. Un problema recurrente sigue siendo asimismo el de la conexión entre objeto de la reclamación y responsabilidad del demandado, en particular con respecto a los subrogados de los bienes hereditarios perdidos o enajenados (lo que a su vez tiene que ver con el alcance del principio de subrogación real en el régimen clásico de la institución), y a los frutos de la herencia, ya que el hecho de poseer tales objetos, si bien puede abrir el paso al ejercicio de la acción, no necesariamente han de formar parte del objeto de la restitución, lo que en las fuentes no siempre acaba de estar del todo claro. También el juego del SC. Juvenciano continúa siendo fuente permanente de interrogantes; por un lado, el alcance de su aplicación a las peticiones de herencia entre privados (es decir, la j u v e n c i a n i z a c i ó n de la hereditatis petitio), cuándo fue realmente asumida por los clásicos y hasta qué punto modificó la regulación anterior, cómo se produjo la convivencia entre las reglas juvencianas y las anteriores en relación con la responsabilidad del poseedor hereditario (particularmente del bonae fidei prossessor) y la presumible lucha de escuelas entre la interpretación de Juliano y la de Publio Juvencio Celso ${ }^{106}$, o la hipotética coexistencia contradictoria en los textos justinianeos de reglas referentes específicamente a la hereditatis petitio civil y reglas atinentes a la bonorum possessio y a la hereditatis petitio possessoria (lo que, a su vez, se pone en relación con el controvertido tema de la clasicidad de esta última $)^{107}$. Y, por último, otro problema objeto de numerosos análisis desde la Pandectística, pero aún sumido en sombras de penumbra, es el de la concurrencia de las acciones hereditarias y las acciones singulares referidas a los bienes y derechos de la herencia, y sobre todo el perímetro de la compleja actuación de la exceptio "quod praeiudicium hereditati non flat" (Gai. 4, 133, cfr. LENEL, EP., pp. 505 s.; Ulp. D. 5, 3, 25, 17).

Además de estas cuestiones estructurales aún controvertidas, siguen existiendo numerosas sospechas de interpolación en muchos textos de esta sede que

${ }^{104}$ Lenel, Otto, Die Passivlegitimation bei der "hereditatis petitio", en ZSS., 46 (1926), pp. 1 ss.

${ }^{105}$ V.gr. Kaser, Max, Pro herede, cit. (n. 42), pp. 242 ss.

${ }^{106}$ Véase una síntesis en KASER, Max - KNÜTEL, Rolf - LoHSSE, Sebastian, Römisches Privatrecht. Ein Studienbuch (21 a ed., München, 2017), p. 427.

${ }^{107}$ Talamanca, Mario, Istituzioni, cit. (n. 8), p. 704. 
requerirían de un examen renovado: v.gr. Diocl. CI. 3, 31, 7 pr.; Ulp. D. 5, 3, 5, 2; eod. 30, 6a/6d; Iul.-Ulp. D. 5, 3, 16, 4/7; Paul. D. 6, 1, 27, 3 ; 5, 3, 38 ; CI. $7,39,3$; etc.

3. Y fuera de estos casos de dudas, controversias e incertidumbres en el seno de la doctrina romanista, aún hay diversos extremos de esta institución que carecen de un estudio monográfico en profundidad, a la vista del conjunto de las fuentes y las investigaciones más recientes, en otros aspectos conexos. Tal es el caso, en particular, de ciertos aspectos procedimentales, como es la tramitación de la hereditatis petitio en la cognitio extra ordinem y en el procedimiento romano-tardío, o la operatividad de la prescripción de la acción. Asimismo, otras cuestiones más sustanciales, como las conexiones entre la hereditatis petitio y la hereditas iacens o la querela inofficiosi testamenti; los diversos supuestos de concesión de la acción en via utilis (v. gr. el caso del comprador de la herencia, del fideicomisario que adquiere la herencia parvo pretio, del marido poseedor de la herencia pro dote, etc.); los problemas del prelegado en relación con el objeto de la petitio, o la verdadera incidencia de la litis contestatio o la controversia mota con relación a la responsabilidad del demandado. Y, por supuesto, están necesitadas de investigaciones específicas las figuras paralelas de la hereditatis petitio possessoria (D. 5, 4), la $h$. $p$. fideicommissaria (D. 5, 6) y el interdictum quorum bonorum (D. 43, 2).

4. En definitiva que, como puede comprobarse, la acción de petición de herencia continúa siendo una institución fascinante del derecho romano histórico, llena de recovecos y opacidades, que presumiblemente seguirá suscitando por mucho tiempo la intriga de los investigadores interesados en la comprensión profunda y productiva de nuestra tradición romanista en el contexto de un derecho cada vez más global.

BiBLIOGRAFÍA

Albanese, Bernardo, La successione ereditaria in diritto romano antico, en AUP., 20 (1949), pp. 382 ss.

Albertario, Emilio, "Actio de universitate"e "actio specialis in rem" [1919], ahora, en ÉL MISMO, Studi di diritto romano (Milano, 1946), IV, pp. 65-95, 219-235, 385-420.

Ambrosino, Rodolfo, "In iure cessio hereditatis". Spunti per la valutazione della "hereditas", en SDHI., 10 (1944), pp. 1-100.

ANDRÉS SANTOS, Francisco Javier, Subrogación real y patrimonios especiales en el derecho romano clásico (Valladolid, 1997).

- Claves romanistas de la legitimación pasiva en la acción de petición de herencia, en Actas del III Congreso Iberoamericano de derecho romano (León, 1998), pp. 27-35.

Babusiaux, Ulrike, Papinians "Quaestiones". Zur rethorischen Methode eines spätklassischen Juristen (München, 2011).

BEHRENDS, Okko, Die Trichotomie "actio, petitio, persecutio". Ihre Bedeutung für das Verhältnis zwischen philosophischer Rhetorik und klassischer Jurisprudenz und deren Theorie des prozessabwendenden Vergleichs, en Hausmann, Jost - Krause, Thomas (eds.), "Zur Erhaltung guter Ordnung". Beiträge zur Geschichte von Recht und Justiz. Fs. Sellert (Köln - Weimar - Wien, 2000), pp. 11-66.

BIONDI, Biondo, Diritto ereditario romano: parte generale (Milano, 1954). 
Bonfante, Pietro, Corso di diritto romano. VI: Le successioni. Parte generale (Roma, 1930).

Burdese, Alberto, rec. de L. Solidoro Maruotti, La tutela del possesso in età costantiniana (1998), en Recensioni e commenti: sessant'anni di letture romanistiche (Padova, 2009), pp. 304-314.

Calonge Matellanes, Alfredo, Los “iuris possessores"legitimados pasivos a la "hereditatis petitio", en Estudios Álvarez Suárez (Madrid, 1978), pp. 29-44.

CARDIlli, Riccardo, La nozione giuridica di "fructus" (Napoli, 2000).

Casinos Mora, Francisco Javier, De "Hereditatis Petitione". Estudios sobre el significado y contenido de la herencia y su reclamación (Madrid, 2006).

- La repercusión del senadoconsulto Juvenciano en materia de reclamación de herencia, en REHJ., 23 (2001), pp. 53-74.

Castro Sáenz, Alfonso, La herencia yacente en relación con la personalidad jurídica (Sevilla, 1998).

Catalano, Pierangelo, Diritto e persone: studi su origine e attualità del sistema romano (Torino, 1990), I.

Codina Rossa, Maria Dolores, La acción de petición de herencia (Barcelona, 2007).

D'Ors, Álvaro, Derecho privado romano (10ª ed., Pamplona, 2004).

De la Rosa, Pelayo, Hereditatis petitio, en Estudios Iglesias (Madrid, 1978), III, pp. 1255-1272.

Díaz BaUtisTa, Antonio, La buona fede nel Senatoconsulto Giuvenziano, en Il ruolo della buona fede oggettiva nell'esperienza giuridica storica e contemporanea: Atti del Convegno Internazionale di Studi in onore di Alberto Burdese (Padova, Venezia, Treviso, 14-15-16 giugno 2001) (Padova, 2003), I, pp. 489-504.

GonZÁlez Roldán, Yuri, El principio "dolus pro possessione est" en la perspectiva del senadoconsulto Juvenciano, en Revista de Investigaciones Jurídicas, 27 (México, 2003), pp. $309 \mathrm{~s}$

—Il senatoconsulto "Giuvenziano”, en SDHI., 72 (2006), pp. 118 ss., 158 ss.

-Il senatoconsulto "Q. Iulio Balbo et P. Iuventio Celso consulibus factum" nella lettura di Ulpiano (Bari, 2008).

- La responsabilidad del poseedor de buena fe respecto a los frutos e intereses en la perspectiva del senadoconsulto Juvenciano, en Anuario Mexicano de Historia del Derecho, 15 (2003), pp. 675-715.

- La subrogación del precio a las cosas hereditarias en la perspectiva del senadoconsulto Juvenciano, en Revista de Investigaciones Jurídicas, 28 (México, 2004), pp. 241-271.

- Senatusconsultum Iuventianum. Apuntes para la reconstrucción de un litigio fiscal en la época de Adriano, en Revista de Investigaciones Jurídicas, 22 (México, 1998), pp. 139-187.

- La apelación frente al senado en la edad de Adriano. Una teoría con base en D. 5.3.20.6, en Revista de Investigaciones Jurídicas, 25 (México, 2001), pp. 229-283.

González-Palenzuela Gallego, María Teresa, Las impensas en el derecho romano clásico (Cáceres, 1998).

GuZMÁn BRITO, Alejandro, Derecho privado romano (Santiago de Chile, 1996), II.

HACKL, Karl, "Praeiudicium" im klassischen römischen Recht (Salzburg, 1975).

Impallomeni, Gianbattista, voz Successioni. Diritto romano, en NNDI., (Torino, 1971), XVIII, pp. 704-727.

KASER, Max, Die Passivlegitimation zur "hereditatis petitio", en ZSS., 72 (1955), pp. $90-127$ 
—Pro herede vel pro possessore, en Studi Biscardi (Milano, 1982), II, pp. 221-260.

—Das römisches Privatrecht (2a ed., München, 1971-1975), I y II.

—Nochmals über Besitz und Verschulden bei den "actiones in rem", en ZSS., 98 (1981), pp. 77-146.

—Controversiam movere, en St. Sanfilippo (Milano, 1982), II, pp. 215-271.

KASER, Max - HACKL, Karl, Das römische Zivilprozessrecht (2a ed., München, 1996).

KaSER, Max - KNÜTel, Rolf - LoHSSE, Sebastian, Römisches Privatrecht. Ein Studienbuch (21 a ed., München, 2017).

Kuingenberg, Georg, Das "Edictum divi Marci de rebus alienis a fisco distractis", en RIDA., 34 (1987), pp. 181-220.

Lenel, Otto, Die Passivlegitimation bei der "hereditatis petitio", en ZSS., 46 (1926), pp. 1-18.

LIEBS, Detlef, Gemischte Begriffe im römischen Recht, en Index, 1 (1970), pp. 143-177.

Longo, Gianetto, L'hereditatis petitio (Padova, 1933).

—rec. a Quadrato, Hereditatis petitio possessoria (1972), en Iura, 23 (1972), pp. 271275.

Luchetti, Giovanni, I primi due libri del commentario di Paolo "ad edictum". Parte seconda, en Studi Martini (Milano, 2009).

Müller-Ehlen, Martina, "Hereditatis petitio". Studien zur Leistung auffremde Schuld und zur Bereicherungshaftung in der römischen Erbschaftsklage (Köln, 1998).

Quadrato, Renato, Hereditatis Petitio Possessoria (Napoli, 1972)

—Voz Petizione di eredità (diritto romano), en ED., 33 (Milano, 1983), pp. 609-616.

Robbe, Ubaldo, La successio e la distinzione fra "successio in locum" e "successio in ius" (Milano, 1965), I.

SCHIPANI, Sandro, Responsabilità del convenuto per la cosa oggetto di azione reale (Torino, 1971).

Schulz, Fritz, Prinzipien des römischen Rechts (München, 1934).

SCHWARZ, Fritz, Studien zur "hereditatis petitio", en TR., 24 (1956), pp 279-323.

Selb, Walter, en Honsell, Heinrich - Mayer-Maly, Theo - Selb, Walter, Römisches Recht, aufgrund des Werkes von Paul Jörs, Wolfgang Kunkel und Leopold Wenger (Berlin, 1987).

SIRACUSA, Raffaella, L' "actio de universitate" nell'ambito della concezione romana dell' "hereditas" come "universitas", en SDHI., 66 (2000), pp. 119-146.

-Il fenomeno delle "actiones de universitate" tra diritto classico e diritto bizantino, en Il diritto giustinianeo fra tradizione classica e innovazione Atti del Convegno Cagliari, 13-14 ottobre 2000 (Cagliari, 2003), pp. 271-285.

—La nozione di "universitas" in diritto romano (Milano, 2016).

Solidoro Maruotti, Laura, La tutela del possesso in età costantiniana (Napoli, 1998).

SPENGLer, Hans-Dieter, Studien zur "interrogatio in iure" (München, 1994).

Talamanca, Mario, Studi sulla legitimazione passiva alla "hereditatis petitio" (Milano, 1956).

—Osservazioni sulla legitimazione passiva alle "actiones in rem", en Studi Cagliari, 43 (1964), pp. 133-187.

—Note sulla "oblatio liti", en SprUIT, Jan E. (ed.), "Maior viginti quinque annis". Essays in Commemoration of the Sixth Lustrum of the Institute for Legal History of the University of Utrecht (Assen, 1979), pp. 167-201.

- Istituzioni di diritto romano (Milano, 1990).

VocI, Pasquale, Diritto ereditario romano (2a ed., Milano, 1963), I. 
Watson, Alan, The Law of Succession in the Later Roman Republic (Oxford, 1971). Welle, Arno, "In universalibus pretium succedit in locum rei, res in locum pretii". Eine Untersuchung zur Entwicklungsgeschichte der dinglichen Surrogation bei Sondervermögen (Berlin, 1987).

Zimmermann, Edward, Beitrag zur Lehre der "hereditatis petitio", en Archiv für die Civilistische Praxis, 29 (1846), pp. 212-233.

Zucсотті, Ferdinando, "Fruges fructusque": (studio esegetico su D. 50. 16. 77): per una ricerca sulle origini della nozione di "frutto" (Padova, 2000). 